\section{Subacute Combined Degeneration of the Dorsal Columns in A Patient With Nitrous Oxide Induced B12 Inactivation: A Case Report}

\section{Abstract}

Nitrous oxide $\left(\mathrm{N}_{2} \mathrm{O}\right)$ toxicity is a well-known entity. It is capable of inactivating vitamin B12, producing a relative B12 deficiency. Vitamin B12 is needed for neurologic development and is necessary for the body to complete vital biologic functions. We look at a case of a 28 year old patient who abused $\mathrm{N}_{2} \mathrm{O}$, then went on to develop neurologic symptoms of ataxia, numbness and subacute combined degeneration of the dorsal columns as seen on MRI. Her symptoms were consistent with vitamin B12 deficiency despite having normal vitamin B12 levels by conventional lab measurements. Her methylmalonic acid (MMA) levels however were elevated. After administering daily B12 injections for 2 weeks and complete abstinence from $\mathrm{N}_{2} \mathrm{O}$, her neurologic deficits have nearly resolved.

Keywords: Nitrous oxide; B12 deficiency; MRI; Neurology

Received: September 28, 2015; Accepted: October 31; 2015, Published: October 31, 2015

\section{Introduction}

Nitrous oxide $\left(\mathrm{N}_{2} \mathrm{O}\right)$ is an inhaled colorless gas which has been commonly used as an anesthetic since the $19^{\text {th }}$ century [1]. It was first discovered in the late $18^{\text {th }}$ century and used as a recreational drug [2], and is known to cause states of euphoria and analgesia [3]. The practice of inhaling $\mathrm{N}_{2} \mathrm{O}$ recreationally is known as 'whippets,' 'nozzing 'and 'hippie crack' [4]. Global drug surveys done in the UK showed that up to $20.4 \%$ of responders used $\mathrm{N}_{2} \mathrm{O}$ in the year 2014 [4]. In the United States, while it is not illegal to own or purchase $\mathrm{N}_{2} \mathrm{O}$, it is illegal to inhale or possess $\mathrm{N}_{2} \mathrm{O}$ with the intent of inhaling it [5].

Although $\mathrm{N}_{2} \mathrm{O}$ toxicity is a recognized entity, it is the purpose of this case report to reinforce this fact and present a unique case of $\mathrm{N}_{2} \mathrm{O}$ toxicity. We present the case of a 28 year old female who had been abusing $\mathrm{N}_{2} \mathrm{O}$ regularly. After having a dental procedure under $\mathrm{N}_{2} \mathrm{O}$ analgesia, she developed acute onset ataxia, numbness and severe subacute combined degeneration of the dorsal columns as evidenced by MRI, despite having apparently normal B12 levels.

\section{Case Presentation}

Our patient was a 28 year old white female, non-vegetarian who presented to the hospital on the $29^{\text {th }}$ of April, 2015 with chief

\section{Eugene R Jalbert II, \\ D.O. Amir Fahmi, \\ D.O. Carol Li, \\ D.O. Mana Goshtasbi, \\ M.D. Mohammed Zaman, \\ D.O}

Nova Southeastern University: Largo

Medical Center, Largo, FL, USA

Corresponding author: Eugene R Jalbert

Đ Genejalbert@gmail.com

Largo Medical Center, Graduate Medical Education Largo, FL, USA.

Tel: 7276000841

Citation: Jalbert ER, Fahmi DOA, Li DOC, et al. Subacute Combined Degeneration of the Dorsal Columns in A Patient With Nitrous Oxide Induced B12 Inactivation: A Case Report. J Neurol Neurosci. 2016, 6:3. complaint of numbness which extended from her mid chest and extended down both arms and both legs beginning four days prior to arrival. The symptoms were slow in onset and progressively worsened after seeing her orthodontist for a tooth extraction. $\mathrm{N}_{2} \mathrm{O}$ was used during this procedure. Additionally she complained of fatigue, difficulty walking, and maintaining her balance. Physical examination revealed an equivocal Romberg's sign, gross ataxia, and decreased sensation below the mid chest region extending down both arms and down both legs.

Past medical history was suggestive of a benign breast mass for which she had undergone surgery. Also, there was a history of general anxiety disorder. Social history included social alcohol use, weekly marijuana use, tobacco abuse (smoking one pack per day for the last 14 years), and use of $\mathrm{N}_{2} \mathrm{O}$ inhalation (at least twice weekly for approximately six months). The family history only revealed cancer of unknown etiology on the father's side.

Her laboratory investigation reports were grossly normal, with the following being of note: MCV of $105.3 \mathrm{fL}$ (normal range 84.5-101.5), WBC of $13.7 \mathrm{~K} / \mathrm{uL}$ (normal range 4.2-11.1), UDS was positive for opiates, benzodiazepines, and marijuana. 
Hemoglobin levels were $13.7 \mathrm{gm} / \mathrm{dL}$ (normal range 11.4-15.1). Neither a CT scan of the brain without contrast nor an MRI scan of the brain without contrast showed indications of pathology. MRI of the cervical spine with and without contrast (Figure 1a and 2a) showed increased $\mathrm{T} 2$ weighted signal in the dorsum aspect of the cervical spinal cord from C3 through T1.

Further workup revealed a normal erythrocyte sedimentary rate and c-reactive protein levels. Due to the elevated $\mathrm{MCV}$, folate and B12 levels were checked. Folate was $>24 \mathrm{ng} / \mathrm{mL}$ (Normal $>1.1$ ). Vitamin B12 levels were $367 \mathrm{pg} / \mathrm{mL}$ (normal range 211911). Methylmalonic acid levels were $2501 \mathrm{nmol} / \mathrm{L}$ (normal range 0-378). Review of the chart revealed an MCV of 101.3 in February of the same year.

On day three of the patient's stay, she was started on intramuscular B12 injections. She was given 1000 mcg of B12 daily. Our patient was hospitalized for a total of 6 days. The ataxia improved daily until she was able to walk without the assistance of a rolling walker. The sensation deficits persisted on discharge. $1000 \mathrm{mcg}$ of B12 was administered IM daily for an additional 2 weeks. In the weeks after discharge, she followed up with a primary care physician. Her B12 measurements were within normal levels and she was started on oral B12 supplementation. A phone interview with the patient revealed complete resolution of the ataxia by week 3. She had minimal sensation abnormalities, but they continued to improve daily. She denied continued abuse of $\mathrm{N}_{2} \mathrm{O}$.

\section{Discussion}

Mean corpuscular volume (MCV) is a lab measurement used to determine the different etiologies of anemia. It is a direct measurement of the average size of the red blood cells. Low MCV values are seen with anemia of chronic disease, thalassemias, and most commonly iron deficiency anemia [6]. High MCV values can be associated with cirrhosis, hypothyroidism, myelofibrosis and reticulocytosis [6]. Additionally, MCV values are elevated in vitamin B12 and folate deficiency [6]. Given the clinical scenario and lack of evidence for other causes it was determined that her

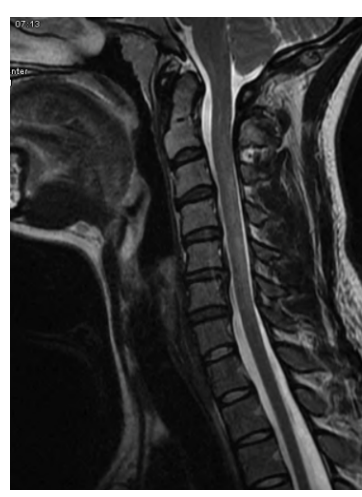

(a)

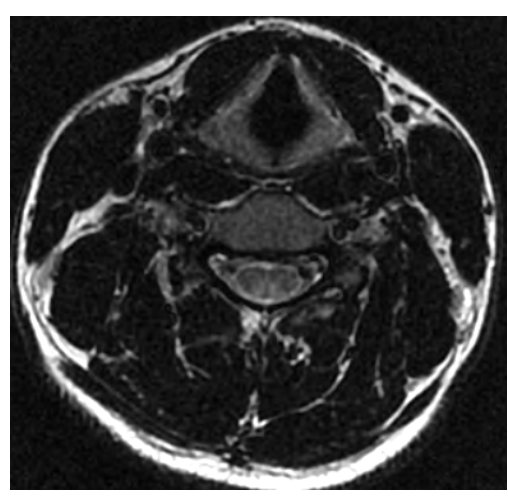

(b)
Figure 1 a) MRI T2 weighted sagittal view of the cervical spine showing increased $\mathrm{T} 2$ signal within the dorsal aspect of the cervical spinal cord from C3 to C7.

b) MRI T2 weighted axial images at the level of at the level of C5.
MCV was likely elevated due to an underlying B12 deficiency due to $\mathrm{B} 12$ inactivation by $\mathrm{N}_{2} \mathrm{O}$. As mentioned in the scenario our patients MCV was 101.3 nearly three months before her presentation above and increased to 105.3 after cumulative and frequent doses of $\mathrm{N}_{2} \mathrm{O}$. If there was a lack of response to treatment a bone marrow biopsy and further testing such as intrinsic factor antibodies would be justified.

Within the body, vitamin B12 exists in both active and inactive forms. The active forms of B12 are methylcobalamin and adenosylcobalamin [7]. In its active form, B12 has two main functions. The neuropathologic importance of B12 is in maintaining myelin sheath formation of neurons. Methylcobalamin is a cofactor for the enzyme methionine synthase [8]. Without methionine synthase, methionine production is halted. Methionine is a precursor to S-adenosylmethionine, which is necessary for the methylation of myelin sheath phospholipids [7] (Figure 2a). Another major role of B12 is the conversion of L-methylmalonyl coenzyme A into succinyl coenzyme A (Figure 2b) [9].

$\mathrm{N}_{2} \mathrm{O}$ is generally considered a safe natural gas, but with cumulative and heavy doses there are potential side effects that must be understood. The first reported case of $\mathrm{N}_{2} \mathrm{O}$ toxicity was published in the Lancet in 1956 [1]. Since 1956, there have been many published reports of both occupational and recreational exposure to $\mathrm{N}_{2} \mathrm{O}$ with subsequent toxicity [1]. Significant use of this gas can lead to a relative B12 deficiency. Mechanistically, $\mathrm{N}_{2} \mathrm{O}$ irreversibly oxidizes cobalamin into inactive forms [10]. Clinically however, B12 deficiency might not be so evident. Simply looking at its measured values may mislead the investigator into believing the B12 levels are normal. The reason for this is that laboratory measurements include both the active and inactive forms of B12 [6].

While our patient in the vignette did not have an underlying B12 deficiency by lab measurements, a repetitive and cumulative exposure to $\mathrm{N}_{2} \mathrm{O}$ placed her at increased risk for $\mathrm{B} 12$ inactivation. Two articles have been published reporting myeloneuropathy in patients exposed to $\mathrm{N}_{2} \mathrm{O}$ in spite of having normal $\mathrm{B} 12$ levels [11,12]. Our patient's B12 levels were normal; however methylmalonic levels were checked and were nearly seven times

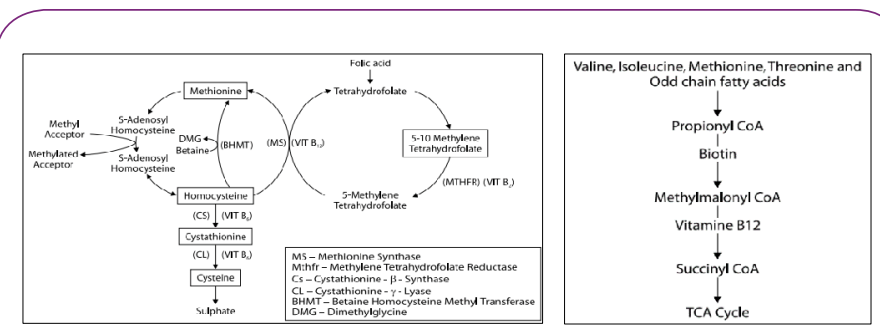

(a)

(b)

Figure 2 a) Diagram showing the importance of Vitamin B12 for the conversion of homocysteine into methionine which is converted to S-adenosylmethionine [12]. b) Diagram showing the importance of Vitamin B12 For the conversion of Methylmalonyl CoA into Succinyl CoA [12]. 
the upper limit of normal. Methylmalonic levels can be elevated in normal individuals rendering it a less specific test. The patient population in which methylmalonic acid is less specific are the elderly and those with a rare autosomal recessive metabolic disorder that is usually diagnosed early in life due to neonatal encephalopathy [6]. Patients who have a B12 deficiency or lack the active form of B12 will almost always an elevated methylmalonic acid level [6]. Laboratory measurement of methylmalonic acid levels as a test is very sensitive for B12 deficiency, but is not specific [6].

A review of the literature reveals that the level of B12 prior to $\mathrm{N}_{2} \mathrm{O}$ exposure can drastically affect the severity of $\mathrm{N}_{2} \mathrm{O}$ toxicity. Pema et. al. in their 1998 article on $\mathrm{N}_{2} \mathrm{O}$ toxicity in the American Journal of Neuroradiology present a very similar case of spinal cord degeneration; however reference that many prior cases had been the cause of underlying "measureable vitamin B12 deficiency" [7]. Other publications indicate that spinal cord degeneration associated with $\mathrm{N}_{2} \mathrm{O}$ abuse is usually found in those with underlying B12 deficiency [10]. It appears that subclinical, but measureable B12 deficiency is the predominant predictor for severity and risk for toxicity when it comes to $\mathrm{N}_{2} \mathrm{O}$ use or abuse. Clinicians should infer that insidious B12 deficiency can become overt when $\mathrm{N}_{2} \mathrm{O}$ is used both appropriately and inappropriately.

\section{Conclusion}

Our patient presented with neurologic deficits consistent with a B12 deficiency in spite of having normal B12 levels. Neurologic and radiographic workup revealed subacute combined degeneration of the cervical spinal cord. Abstinence from $\mathrm{N}_{2} \mathrm{O}$ along with daily B12 injections for two weeks resulted in nearly complete resolution of her symptoms. Our patient had both abused $\mathrm{N}_{2} \mathrm{O}$ and received it medically. $\mathrm{N}_{2} \mathrm{O}$ irreversibly converts $\mathrm{B} 12$ into inactive forms. The $\mathrm{N}_{2} \mathrm{O}$ itself does not cause a deficiency of the vitamin. Frequent and heavy doses of $\mathrm{N}_{2} \mathrm{O}$ can subsequently cause severe and sometimes irreversible degeneration of the spinal cord. Clinicians should recognize that myelopathy after procedures can simply be the result of a B12 deficiency or inactivation. Prompt evaluation and treatment can at times render complete recovery. 


\section{References}

1 Baum V (2007) When nitrous oxide is no laughing matter: nitrous oxide and pediatric anesthesia. Pediatric Anesthesia 17: 824-830.

2 Schmitz G (2013) Use of Nitrous Oxide in the Emergency Department: A Review of the Literature. Emergency Medicine 03.

3 Chiang T, Hung C, Wang W, Lee J, Yang F (2013) Recreational Nitrous OxideAbuse-Induced Vitamin B12 Deficiency in a Patient Presenting with Hyperpigmentation of the Skin. Case Reports in Dermatology 5: 186-191.

4 Northamptonchron.co.uk (2015) 'Legal high' nitrous oxide use discovered in Northampton park. Retrieved 13 June 2015, from http://www.northamptonchron.co.uk/news/local/legal-highnitrous-oxide-use-discovered-in-northampton-park-1-6764182.

5 Cognitiveliberty.org (2015) State Laws Concerning Inhalation of Nitrous Oxide. Retrieved 13 June 2015, from http://www. cognitiveliberty.org/dll/N20_state_laws.htm.

6 Labtestsonline.org (2015) Methylmalonic Acid: Test Sample. Retrieved 13 June 2015, from https://labtestsonline.org/ understanding/analytes/mma/tab/sample.
7 Pema P, Horak H, Wyatt R (1998) Myelopathy Caused by Nitrous Oxide Toxicity. American Journal of Neuroradiology 19: 894-896.

8 Hoffbrand A (2015) Megaloblastic Anemias. In: Longo D, Fauci A, Hauser S, Jameson J, Loscalzo J Harrison's Principles of Internal Medicine $\left(18^{\text {th }}\right.$ edn.) New York, NY: McGraw-Hill. Retrieved from http://accessmedicine.mhmedical.com.Imunet.idm.oclc.org/ content . aspx? bookid=331\&Sectionid $=40726843$.

9 Nitrous Oxide Induced Elevation of Plasma Homocysteine and Methylmalonic Acid Levels And Their Clinical Implications. (2004) IJA 8.

10 Flippo T (1993) Neurologic Degeneration Associated With Nitrous Oxide Anesthesia in Patients With Vitamin B12 Deficiency. Arch Surg 128: 1391.

11 Layzer R (1978) Myeloneuropathy after Prolonged Exposure to Nitrous Oxide. The Lancet 312: 1227-1230.

12 Vishnubhakat S, Beresford H (1991) Reversible myeloneuropathy of nitrous oxide abuse: Serial electrophysiological studies. Muscle \& Nerve 14: 22-26. 